\section{Gold Reference Catalysts}

World Gold Council has taken the initiative in commissioning the preparation of a number of Gold Reference Catalysts, with the main objective of enabling researchers to benchmark their own catalyst formulations.

The Gold Reference Catalysts include three on oxide supports made by Sud Chemie, Japan under the supervision of Dr Masatake Haruta, with characterisation at AIST, Japan under the supervision of Dr Susumu Tsubota. It is also intended that a fourth catalyst based on gold on carbon will be made available.

Each sample contains $10 \mathrm{~g}$ of catalyst and a small charge is made for each sample to cover handling and administration costs. Please see the World Gold Council website at www.gold.org (science and industry section) for latest charges and to order a catalyst.

\section{Gold Reference Catalyst Types}

Each of the catalyst preparations has been characterised with respect to gold loading, gold particle size and catalytic activity in carbon monoxide and hydrogen oxidation tests. These characterisation details will be supplied with the samples.

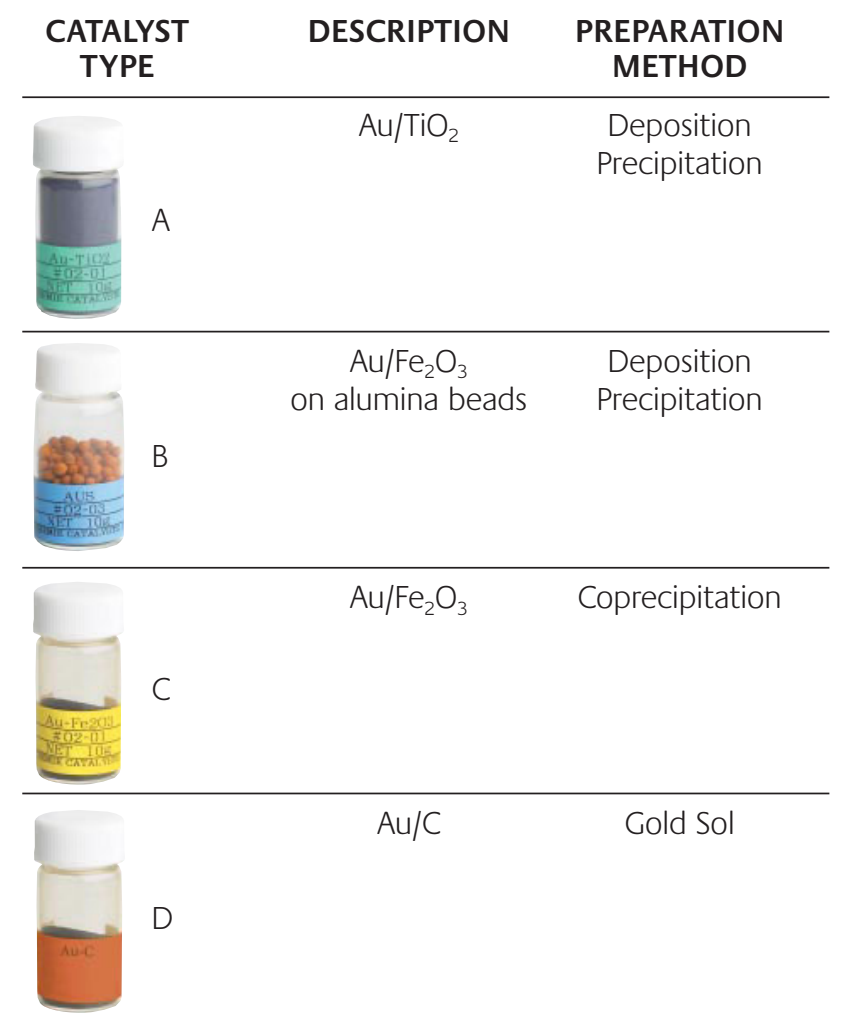

For further information or to order contact: International Technology, World Gold Council, 45 Pall Mall, London, UK. Email: industry@gold.org

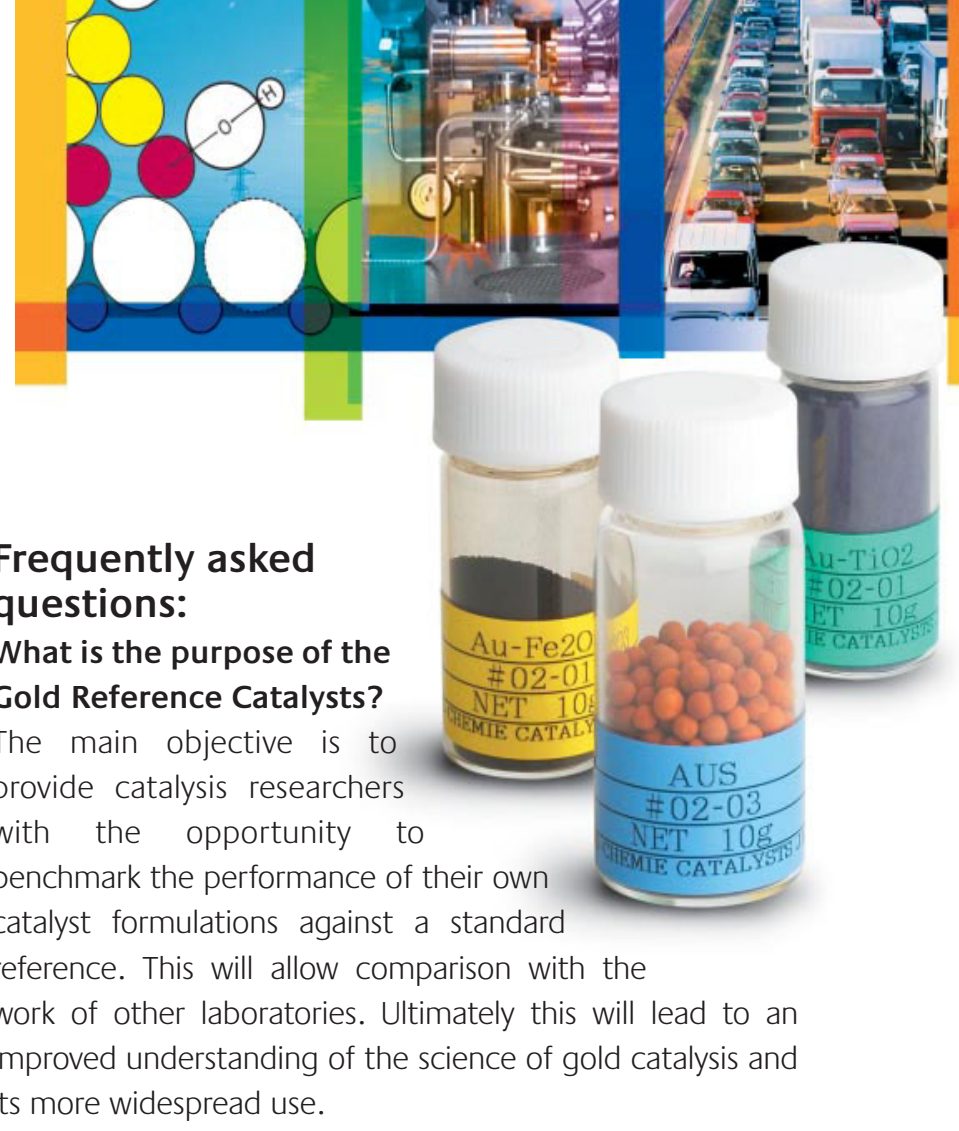

How much do the Gold Reference Catalysts cost?

Catalysts are supplied in $10 \mathrm{~g}$ batches for a nominal charge to cover handling and administration costs. Reduced charges apply for academic institutions. Please check the World Gold Council website at www.gold.org (science and industry section) for latest charges.

Who has manufactured the Gold Reference Catalysts? At the suggestion of Prof Geoffrey Bond, World Gold Council commissioned the preparation of the catalysts early in 2002 . They have been made in Japan by Süd Chemie, under the supervision of Dr Masatake Haruta, with characterisation by Dr Tsubota, AIST.

\section{Who can obtain a Gold Reference Catalyst(s)?}

Any academic or industrial organisation with a relevant interest and subject to acceptance of the programme's Terms and Conditions.

\section{What reactions might the Gold Reference Catalysts be used in?}

Gold has been shown to be a particularly active catalyst (the most active in some cases) for reactions including:

Oxidation of $\mathrm{CO}$ and Hydrocarbons

Selective Oxidation, eg Epoxidation of Olefins

Selective Hydrogenation and Hydrogenation of $\mathrm{CO}$ and $\mathrm{CO}_{2}$

Water Gas Shift (WGS)

Reduction of $\mathrm{NO}$ with Propene, $\mathrm{CO}$ or $\mathrm{H}_{2}$

Reactions with Halogenated Compounds

Hydrogen plus Oxygen Reaction to give $\mathrm{H}_{2} \mathrm{O}_{2}$ or $\mathrm{H}_{2} \mathrm{O}$

The unique advantage of gold catalysts are that they are active at lower temperatures than other catalysts. New reactions continue to be discovered and are regularly reported in CatGold News. 